\title{
Horses as healers for veterans
}

$\mathrm{E}$ quine-assisted psychotherapy may sound like yet another health fad. But the uptake tells another story. There are now more than 600 equine-assisted psychotherapy and learning programs worldwide, and more than 20 in Canada, that help clients deal with conditions ranging from autism to addiction, from eating disorders to depression. Recently, soldiers with post-traumatic stress disorder (PTSD) have begun attending equine therapy, and Veterans Affairs Canada is providing funding for efficacy research to one such program.

Can Praxis, a collaboration based in Alberta, is developing instruments to measure the acquisition of strengthbased life skills and reductions in PTSD symptoms among its veteran clients. Can Praxis' equine-assisted learning program was developed by Steve Critchley, a Canadian Forces veteran and conflict manager, and Jim Marland, an experienced psychologist. So far this year, they have conducted five pilot workshops involving 23 veterans and 20 spouses.

Don Wood and Lisa Conrod flew from Shearwater, Nova Scotia, to Rocky Mountain House, Alberta, to participate in one of the three-day workshops. Don got a diagnosis of PTSD in 2008 and has been undergoing psychotherapy through the military for five years now. When Conrod first told Wood about the workshop, he was skeptical, but through conversations with Critchley, Wood saw

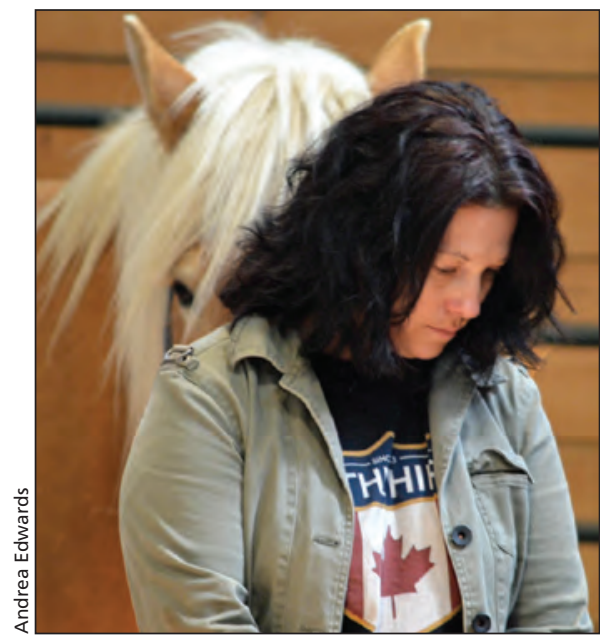

Lisa Conrod and her partner Don Wood, a veteran with post-traumatic stress disorder, participated in a three-day equine therapy workshop in Alberta. the potential value in a program designed for both him and his spouse.

In reflecting on what made the Can Praxis program unique, Wood highlights the peaceful setting, which is "not anything near anything military," the self-mediation skills he was taught and the horses.

"When you're frustrated, they get nervous and scared. They sense your stress, even though you try to hide it."

The program is delivered at zero cost to participants. Initial sessions are sponsored by Wounded Warriors, a nonprofit that helps Canadian Forces members who have been wounded or injured in service.

In May 2013, Veterans Affairs Canada pledged \$25000 to Can Praxis to help them evaluate the effectiveness of animal-assisted interventions that support veterans' recovery. Media relations officer Simon Forsyth says, "The pilot will develop and test measurement tools that will assist in future research on the effectiveness of animal-assisted interventions."

Dr. Randy Duncan is a coinvestigator on the project and played a lead role in writing the funding proposal to Veterans Affairs Canada. He says they developed tools to measure the outcomes of the program, which include acquisition of skills and knowledge as well as improvement in symptoms of PTSD.

Can Praxis has applied for up to $\$ 50000$ in additional funding through the Horses and Humans Research Foundation to continue pilot testing into 2014. Duncan hopes to provide an acceptable sample size for the analyses and validation process by having approximately 100 participants both veterans and their spouses or partners - through the program.

Other research has found that horseassisted therapy often yields results. For example, a 2012 Canadian Agency for Drugs and Technologies in Health report concluded it was effective in helping children who experience family violence, patients with schizophrenia and children with attentiondeficit/hyperactivity disorder. - Erin Russell, CMAJ

CMAJ 2013. DOI:10.1503/cmaj.109-4578 